\title{
Erratum
}

\section{Erratuum to Preparation of ZnS-CdS Nanocomposite for Photoelectrochemical Hydrogen Production [Int. J. Electrochem. Sci., 12 (2017) 2253-2261]}

Jingyi Xu

Henan Polytechnic Institute, NO.666 Kongming Road, Nanyang, Henan, China.

E-mail: hnpi-jingyi@qq.com

Received: 18 March 2016 / Accepted: 18 March 2017 / Published: 12 April 2017

The author regret that there were errors in the original published version.

The affiliation of Jingyi Xu was not assigned correctly in the paper and the correct affiliation should be

"Henan Polytechnic Institute, NO.666 Jiankang Road, Nanyang, Henan, China".

This was not noticed at the time by the author and it is corrected by this erratum now, and I apologize for any inconvenience this may cause.

The correct paragraph is as follows:

Jingyi $X u$

Henan Polytechnic Institute, NO.666 Jiankang Road, Nanyang, Henan, China.

E-mail: hpi-jingyi@qq.com

(C) 2017 The Authors. Published by ESG (www.electrochemsci.org). This article is an open access article distributed under the terms and conditions of the Creative Commons Attribution license (http://creativecommons.org/licenses/by/4.0/). 